\title{
Complex Regional Pain Syndrome Acceptance and the Alternative Denominations in the Medical Literature
}

\author{
Jasmina Todorova $^{a}$ Nikolaj Dantchev ${ }^{a}$ Guenka Petrova $^{\mathrm{b}}$ \\ Departments of a Pharmacology, Pharmacotherapy and Toxicology and ${ }^{b}$ Social Pharmacy and \\ Pharmacoeconomics, Faculty of Pharmacy, Medical University Sofia, Sofia, Bulgaria
}

\section{Key Words}

Complex regional pain syndrome $\cdot$ Reflex sympathetic dystrophy $\cdot$ Causalgia $\cdot$ Terminology $\cdot$ Nomenclature $\cdot$ Medicine $\cdot$ Humans

\begin{abstract}
Objective: To analyze the use of the term 'complex regional pain syndrome' in the medical literature and evaluate whether or not the traditional names 'reflex sympathetic dystrophy' and 'causalgia' have already been replaced with the new terms 'complex regional pain syndrome type $\mathrm{I}$ ' and 'complex regional pain syndrome type II', respectively. $\mathbf{M a -}$ terials and Methods: The Scopus and PubMed databases were searched for reports written between 2001 and 2012 for the following descriptors in the titles: 'complex regional pain syndrome', 'complex regional pain syndrome type l', 'complex regional pain syndrome type 1', 'complex regional pain syndrome type II', 'complex regional pain syndrome type 2,, 'CRPS', 'CRPS type I', 'CRPS type 1', 'CRPS type II', 'CRPS type 2', 'reflex sympathetic dystrophy', 'algodystrophy', 'algoneurodystrophy', 'causalgia', 'transient osteoporosis', 'Sudeck', and 'shoulder-hand syndrome'. Results: Systematization of the 1,318 articles found yielded the following: 953 (72.31\%) articles for the descriptor 'complex regional pain syndrome' and a further 94 (7.13\%) for its abbreviation 'CRPS'; $180(13.66 \%)$ for 'reflex sympathetic dystrophy'; 33 (2.50\%)
\end{abstract}

\section{KARGER}

E-Mail karger@karger.com www.karger.com/mpp

\section{(c) 2012 S. Karger AG, Basel} 1011-7571/13/0223-0295\$38.00/0

Karger

Open access

This is an Open Access article licensed under the terms of the Creative Commons Attribution-NonCommercial-NoDerivs 3.0 License (www.karger.com/OA-license), applicable to the online version of the article only. Distribution for non-commercial purposes only. for 'shoulder-hand syndrome'; 29 (2.20\%) for 'algodystrophy'; 13 (0.99\%) for 'causalgia'; 13 (0.99\%) for 'Sudeck'; 2 (0.15\%) for 'algoneurodystrophy', and 1 (0.08\%) for 'transient osteoporosis'. The total number of articles using new terminology represents 1,047 (79.44\%) of all articles. Conclusion: The new neutral term 'complex regional pain syndrome' was most commonly used and will likely replace the traditional names 'reflex sympathetic dystrophy' and 'causalgia'. The new terminology is now widely accepted by the medical professionals who are mostly engaged in the treatment of CRPS patients, but not yet so in other medical spheres.

Copyright $\odot 2012$ S. Karger AG, Base

\section{Introduction}

Denominations of diseases provide a tool for their identification and are thus almost as important as their treatments. Some names of diseases point to a framework of the contemporary understanding of their etiology, pathophysiology, genetics, immunology, and clinical characteristics. Therefore, the use of the exact terminology in clinical practice and research is crucial for pertinent medical communication. This, however, is problematic in the case of complex regional pain syndrome (CRPS), since there are a wide variety of terms used for the syndrome. 
In the 17th and 18th centuries, several references can be found in the literature describing some symptoms of a syndrome first presented in detail by S.W. Mitchell [1] in 1864 and named by him 'causalgia'. Ever since, the syndrome has been a subject of interest to researchers, who have contributed to the knowledge of what is now called 'complex regional pain syndrome'. Since it was first described, there have been many attempts to find an adequate name for the condition, and as a result the syndrome has been given many names related, for example, to its initializing event, pathogenetic mechanisms, clinical expression, specialty of the authors or their country of origin, etc. [2]. Nowadays, there are as many as 79 names for the syndrome in the English literature, 49 in German, 32 in French, 14 in Dutch, 13 in Italian, 10 in Bulgarian, and 5 in the Russian literature $[3,4]$. The most popular names until the end of the 20th century were 'reflex sympathetic dystrophy' and 'causalgia' [5]. It may be inferred that this is the syndrome with the most names in medical literature, which causes misunderstanding and difficulties for everybody - clinicians, researchers and patients.

The term 'reflex sympathetic dystrophy' was introduced in the mid-20th century as a result of the hypothesis that the sympathetic nervous system plays a key role in the development and maintenance of pain and the other symptoms of the syndrome, and has gained widespread support over the years. However, by the end of 20th century, it became obvious that this term was incorrectly used, as not all patients experience sympathetically maintained pain. This has been proved by the evidence of the lack of effect from the sympathetic blocks and because not all the cases develop dystrophic changes [6]. Therefore, the term 'reflex sympathetic dystrophy' has lost its significance as a clinical entity [7]. Moreover, it has become apparent that the sympathetic nervous system is not the only mechanism involved in the pathophysiology of the disease. Nevertheless, it has become increasingly accepted that there are multiple mechanisms involved [8] and that CRPS has been recognized rather as a disease of the central nervous system as well [9].

In 1993, in order to eliminate the increasing inaccuracy and dissatisfaction of the term 'reflex sympathetic dystrophy', a consensus conference of the International Association for the Study of Pain (IASP) was held. As a result, a neutral term 'complex regional pain syndrome', which evaded mention of the etiological, pathophysiological or clinical features of the syndrome, was introduced [7]. Since then, 'reflex sympathetic dystrophy' has been termed 'complex regional pain syndrome type I' (CRPS I), while what was previously known as 'causalgia' be- came 'complex regional pain syndrome type II' (CRPS II). The differentiation between the two types of CRPS is based on whether or not a nerve lesion is present. If it is, the patient is diagnosed with CRPS II, while if it is not, it is CRPS I [6].

The new terminology needed time to be accepted and applied in medical circles. In 2001, Schott wrote that the term 'complex regional pain syndrome' was not widely familiar outside the IASP circles and that clinicians and researchers were still using the previously established terminology, 'reflex sympathetic dystrophy' and 'causalgia' [10]. Again in 2001, in a study of the acceptance of the new terminology and its impact on the medical literature, $\mathrm{Al}$ vares-Lario et al. [5] reported that 'reflex sympathetic dystrophy' and 'causalgia' were still the most widely used names for the syndrome. Recently, it has been stated that the use of the traditional terminology has been decreasing, and that 'complex regional pain syndrome' is used routinely by pain specialists and increasingly by neurologists [11]. Since then, 19 years have passed since the new terminology was introduced and 11 years since the report of Alvares-Lario et al. was published.

The aim of the current study was to analyze the usage of the term 'complex regional pain syndrome' in the scientific medical literature and to evaluate whether or not the traditional names 'reflex sympathetic dystrophy' and 'causalgia' have already been replaced with their more neutral terms 'complex regional pain syndrome type I' and 'complex regional pain syndrome type II', respectively.

\section{Materials and Methods}

The Scopus and PubMed databases were searched for reports written between 2001 and 2012 that include the following descriptors in the titles: 'complex regional pain syndrome', 'complex regional pain syndrome type I', 'complex regional pain syndrome type 1', 'complex regional pain syndrome type II', 'complex regional pain syndrome type 2', 'CRPS', 'CRPS type I', 'CRPS type 1', 'CRPS type II', 'CRPS type 2', 'reflex sympathetic dystrophy', 'algodystrophy', 'algoneurodystrophy', 'causalgia', 'transient osteoporosis', 'Sudeck', and 'shoulder-hand syndrome'. Other descriptors were excluded because of minimal or no use.

The following data was obtained for each article: author/s, author's address, title, language of the article, year of publication, country of publication, source, and terminology for the syndrome used in the title of the article. Parentheses, medical subject heading major terms and author keywords were registered when available. If more than one descriptor was in the name of the article, and as a result the same article was generated more than once, the article was counted only once, but all the names from the title were registered in the relevant statistics.

The articles were then analyzed with regard to the names used during the 11-year period, according to the country of origin of 
Table 1. Number of titles detected with the different descriptors (parenthetically used terms when available)

\begin{tabular}{|c|c|c|c|c|c|c|c|c|c|c|c|c|c|}
\hline & 2001 & 2002 & 2003 & 2004 & 2005 & 2006 & 2007 & 2008 & 2009 & 2010 & 2011 & 2012 & Total \\
\hline CRPS $^{*}$ & $0(2)$ & $1(1)$ & $3(4)$ & $1(4)$ & $7(3)$ & $4(4)$ & $10(4)$ & $7(5)$ & $2(5)$ & $12(7)$ & $8(9)$ & $8(5)$ & $63(53)$ \\
\hline CRPS $^{*}$ type I/1 & $1(2)$ & $2(1)$ & $2(2)$ & $3(2)$ & $3(0)$ & $3(2)$ & $2(1)$ & $3(3)$ & $3(5)$ & $3(2)$ & $4(7)$ & $1(1)$ & $30(28)$ \\
\hline Complex regional pain syndrome type II/2 & $0(0)$ & $1(1)$ & $2(0)$ & $2(0)$ & $1(1)$ & $3(0)$ & $2(0)$ & $1(0)$ & $2(0)$ & $1(0)$ & $1(0)$ & $1(0)$ & $17(2)$ \\
\hline CRPS $^{*}$ type II/2 & $0(0)$ & $0(0)$ & $0(0)$ & $0(0)$ & $0(0)$ & $1(1)$ & $0(0)$ & $0(0)$ & $0(0)$ & $0(1)$ & $0(0)$ & $0(0)$ & $1(2)$ \\
\hline Algo(neuro)dystrophy & $2(1)$ & $8(3)$ & $1(2)$ & $1(1)$ & $4(2)$ & $3(1)$ & $1(1)$ & $3(0)$ & $5(0)$ & $0(0)$ & $1(1)$ & $2(1)$ & $31(13)$ \\
\hline Shoulder-hand syndrome & $4(0)$ & $0(0)$ & $5(0)$ & $5(0)$ & $2(0)$ & $0(0)$ & $1(0)$ & $5(0)$ & $4(1)$ & $3(0)$ & $2(1)$ & $2(1)$ & $33(3)$ \\
\hline Causalgia & $1(0)$ & $1(1)$ & $4(0)$ & $1(2)$ & $1(0)$ & $1(1)$ & $1(0)$ & $1(1)$ & $1(0)$ & $0(0)$ & $1(0)$ & $0(0)$ & $13(5)$ \\
\hline Sudeck ${ }^{* * *}$ & $1(1)$ & $1(0)$ & $1(2)$ & $0(1)$ & $2(0)$ & $0(1)$ & $0(0)$ & $2(0)$ & $1(0)$ & $3(0)$ & $1(0)$ & $1(0)$ & $13(5)$ \\
\hline Transient osteoporosis & $0(0)$ & $0(0)$ & $0(0)$ & $0(0)$ & $1(0)$ & $0(0)$ & $0(0)$ & $0(0)$ & $0(0)$ & $0(0)$ & $0(0)$ & $0(0)$ & $1(0)$ \\
\hline
\end{tabular}

* Abbreviation for complex regional pain syndrome used in the titles. ${ }^{*}$ Comprises complex regional pain syndromes and complex regional pain syndrome type I or 1 and type II or $2 .{ }^{* *}$ Comprises Sudeck's syndrome, Sudeck's disease, Sudeck's atrophy and Sudeck's dystrophy.

the author and according to the specialty of the journals retrieved. In general, 1,318 articles were found and analyzed in the study. Due to limited space, only the articles cited in the text are included in the reference list. A full list of articles is available upon request from the corresponding author.

\section{Results}

The systematization of the 1,318 articles found is presented in table 1 . The search yielded 953 (72.31\%) articles for the descriptor 'complex regional pain syndrome' and a further $94(7.13 \%)$ for its abbreviation 'CRPS', totally 1,047 (79.44\%); 180 (13.66\%) for 'reflex sympathetic dystrophy', 33 (2.50\%) for 'shoulder-hand syndrome', 29 (2.20\%) for 'algodystrophy', 13 (0.99\%) for 'causalgia,'13 (0.99\%) for 'Sudeck', 2 (0.15\%) for 'algoneurodystrophy', and $1(0.08 \%)$ for 'transient osteoporosis'.

Of the total number of titles containing 'complex regional pain syndrome', in $660(63.04 \%)$ cases the type of syndrome was not defined and in $14(1.34 \%)$ the term 'complex regional pain syndromes' was likely used to define both types. 'Complex regional pain syndrome type I' was specified in 258 (24.64\%) references, in which both Roman and Arabic numbers were used, the Roman ones being used more often (158:100). 'Complex regional pain syndrome type II' related to 17 (1.62\%) titles, 15 of which were written with Roman numbers. In 4 articles the name was written as 'complex regional pain syndrome type I and type II'. The descriptor 'CRPS', without specifying the type, was detected in 63 (6.02\%) articles. In another 30 articles (2.87\%), type I was specified and in 1 case only type II was specified. In this search, the Roman numbers were used more often. The older term 'reflex sympathetic dystrophy' was found in $180(13.66 \%)$ references, with marked gradual decrease in its use over the years. In 23 $(12.78 \%)$ of these titles, other descriptors were found: in 13 of them 'complex regional pain syndrome' or its abbreviated version 'CRPS' with or without 'type I'.

The total number of articles using the new terminology represents $79.44 \%$ of all articles. The number of titles containing 'reflex sympathetic dystrophy' is $13.66 \%$.

The term 'shoulder-hand syndrome' was used in 33 (2.50\%) articles during the 11-year period, most of which described the syndrome in poststroke patients. Twentynine $(2.20 \%)$ reports were found for 'algodystrophy' and $2(0.15 \%)$ for 'algoneurodystrophy' (later discussed together as algodystrophy), predominantly used by French authors or authors from French-speaking countries. 'Causalgia', the name with which the syndrome was first described, was found in $13(0.99 \%)$ articles only, and in 2 $(15.38 \%)$ of them this name was used parenthetically alongside the new terminology 'complex regional pain syndrome type II'. The most recent report with this name was in 2011. The name of Paul Sudeck [12] is connected with $13(0.99 \%)$ reports, most of which originate from Germany. In $6(46.15 \%)$ of the articles, a parenthetical term was used as well: 'complex regional pain syndrome' 4 times and 'reflex sympathetic dystrophy' twice. Only 1 Spanish article from Argentina referred to the syndrome with the descriptor 'transient osteoporosis.' 
Table 2. Number of titles found for each descriptor according to the country of origin of the author

\begin{tabular}{lrrrrrrrrrrrrrrrrr}
\hline & USA & UK & Neth & Ger & Aus & Bel & Can & Chi & Fra & Ita & Jap & Spa & Tur & Pol & Isr & Other \\
\hline CRPS* $^{*}$ & 271 & 70 & 148 & 166 & 31 & 12 & 30 & 3 & 25 & 14 & 46 & 19 & 50 & 6 & 13 & 143 \\
RSD $^{* *}$ & 30 & 8 & 18 & 5 & 2 & 11 & 1 & 2 & 19 & 3 & 3 & 16 & 26 & 9 & 3 & 24 \\
Algodystrophy & 0 & 1 & 0 & 1 & 1 & 3 & 0 & 0 & 10 & 2 & 0 & 1 & 0 & 5 & 0 & 7 & 0 \\
Sudeck** & 0 & 0 & 1 & 8 & 0 & 0 & 0 & 1 & 0 & 0 & 1 & 1 & 0 & 0 & 0 & 1 \\
Causalgia & 3 & 2 & 0 & 0 & 0 & 0 & 1 & 0 & 0 & 0 & 1 & 0 & 0 & 0 & 0 & 6 \\
Shoulder-hand syndrome & 1 & 0 & 0 & 1 & 0 & 0 & 0 & 17 & 2 & 3 & 2 & 1 & 1 & 0 & 0 & 5 \\
\hline
\end{tabular}

Neth = Netherlands; Ger = Germany; Aus = Australia; Bel = Belgium; Can = Canada; Chi = China; Fra = France; Ita = Italy; Jap = Japan; Spa = Spain; Tur $=$ Turkey Pol = Poland Isr $=$ Israel . * Comprises complex regional pain syndrome and CRPS used with or without a type. ${ }^{* *}$ Comprises reflex sympathetic dystrophy and RSD. ${ }^{* * *}$ Comprises Sudeck's syndrome, Sudeck's disease, Sudeck's atrophy and Sudeck's dystrophy.

Table 3. Number of titles detected for each descriptor according to the specialty of the journals retrieved

\begin{tabular}{lrrrrrrrrr}
\hline & Pain & Neurol & Orthop & Rehabil & Rheum & Med & Surg & Radiol & Others \\
\hline CRPS* $^{*}$ & 431 & 163 & 111 & 78 & 42 & 132 & 17 & 14 \\
RSD** & 14 & 15 & 46 & 21 & 20 & 30 & 2 & 12 \\
Algodystrophy & 0 & 1 & 14 & 5 & 4 & 7 & 0 & 0 & 0 \\
Sudeck** & 1 & 2 & 1 & 3 & 0 & 6 & 0 & 0 & 0 \\
Causalgia & 3 & 3 & 1 & 1 & 0 & 1 & 3 & 0 \\
Shoulder-hand syndrome & 0 & 2 & 1 & 19 & 2 & 9 & 0 & 0 \\
\hline
\end{tabular}

Pain = Pain and anesthesiology journals; Neurol = neurology and neurosurgery journals; Orthop = orthopedic, hand surgery, podiatry, plastic surgery, and sport medicine journals; Rehabil = rehabilitation and physical medicine journals; Rheum = rheumatology journals; Med = internal and general medicine journals;
Surg = general surgery journals; Radiol = radiology and nuclear medicine journals. ${ }^{*}$ Comprises complex regional pain syndrome and CRPS used with or without a type. ${ }^{* *}$ Comprises reflex sympathetic dystrophy and RSD. ${ }^{* *}$ Comprises Sudeck's syndrome, Sudeck's disease, Sudeck's atrophy and Sudeck's dystrophy.
The term 'complex regional pain syndrome' and its abbreviation 'CRPS' was used not only by English-speaking authors, which has been reported by Alvares-Lario et al. [5] in 2001, but also by German, Dutch, Japanese and Turkish authors (table 2). 'Reflex sympathetic dystrophy' was still the term applied, albeit with decreasing frequency in the US, Turkey, France and the Netherlands; however, French authors usually prefer 'algodystrophy'. The names 'Sudeck's atrophy', 'Sudeck's dystrophy', 'Sudeck's disease' or 'Sudeck's syndrome' were routinely used by German authors, but significantly less so than the new nomenclature: only 8 (4.42\%) references were found for 'Sudeck' as a descriptor. Similar results were found for the descriptor 'causalgia', which was used mainly by English-speaking authors. 'Shoulder-hand syndrome' was preferred by Chinese authors, who are also mostly rehabilitation specialists. Half of the titles using the new terminology were published by European authors: 528 (50.43\%) compared to 306 (29.23\%) in North American papers.

'Complex regional pain syndrome' or its abbreviated form 'CRPS' are used not only by pain specialists and neurologists, but also by internal medicine specialists (table 3). Furthermore, the use of the new terminology among orthopedic and rehabilitation specialists has increased, although orthopedics still prefer the more classical terms, 'reflex sympathetic dystrophy' and 'algodystrophy'. The term has also been used with increased frequency in recent rheumatological literature.

\section{Discussion}

As suggested by Alvares-Lario et al. [5], it is difficult to change an entity's name overnight. Our study shows that there is strong evidence for the increasing acceptance 
of the new terminology. Alvares-Lario et al. [5] observed in 2001 that the new terminology had not effectively replaced the old; later in 2007 Schott [11] noted that it was used routinely by pain specialists and there was a rise in its usage by neurologists as well, and in 2012 the new terminology is present also in the medical, orthopedic and rehabilitation literature and increasingly so in the rheumatological literature. This is only reasonable, since these specialists are the ones who first encounter CRPS patients and are mostly involved in their treatment. The difficulty and inconvenience which the medical professionals had with the terminology may have motivated their willingness to standardize the communication process among them.

The extensive research, as well as the large body of clinical evidence and the treatment outcomes seen during the last decade since the new terminology was introduced, has led to a better knowledge of the syndrome and contributed to a better understanding of its multifactorial mechanisms [8]. It has become evident that not only the sympathetic nervous system but also inflammation, ischemia, central sensitization, autoimmune mechanisms, cortical reorganization, nerve damage, and neurogenic inflammation are involved in the disease mechanisms [13]. Moreover, it became clear that vitamin C has a prophylactic effect in the prevention of CRPS [14]. The first evidence-based guidelines were created to give strong advice in the diagnosis and treatment of CRPS [15]. Sympathetically maintained pain and sympathetic dysfunction may be involved but are not an essential requirement for the syndrome [7]. This could be the reason for the medical field to be convinced not to use a term any longer that is incomplete and incorrect. In addition, accepting a uniform name for a syndrome which affects people seriously and leads to disability improves the communication among researchers and clinicians, and in this way improves the patient's chance for a correct treatment and better outcome. This shows that the medical community is now ready to accept the new terminology and this change seems more justified than it did 19 years ago. The new terminology is now widely accepted by the medical professionals who are mostly engaged in the treatment of CRPS patients, but not yet so in other medical spheres, for example radiology specialists, as seen in table 3.

Although the new denomination is constantly gaining followers all over the world, there are still controversies about the term. Firstly, it is said that CRPS is a broad diagnosis and the term is too vague $[5,16]$. Secondly, according to Schott [11], the term 'CRPS' may give rise to many questions because there are more complex conditions than CRPS, so the pain caused by CRPS could hardly be more complex than phantom pain or anesthesia dolorosa. Also, given that the painful region can be the whole arm or that in some cases the contralateral or ipsilateral extremity can be affected as well [17], the term 'regional' may not be always the most appropriate. What is more, it may be considered imprecise to use the word 'pain', in view of the fact that the pain intensity may vary and can even be absent [11].

The distinction between both CRPS types is also disputable. Harden et al. [16] did not find statistically significant differences in the frequency of occurrence of any CRPS sign or symptom between type I and type II patients, as distinguished by electromyography findings of approved nerve injury or no nerve injury evidence. Furthermore, in the criteria proposed by them, type I and type II are no longer distinguished, which led Schott to believe that a new term should be created [11]. It is important to point out that an electromyography study reflects only the dysfunction in the large peripheral nerves and cannot detect whether there is possible dysfunction of the small nerve fibers. Recently, Oaklander and Field [18] summarized studies $[19,20]$ and suggested that both CRPS type I and CRPS type II are associated with nerve injury and that persistent CRPS type I may represent a small fiber-predominant mono- or oligoneuropathy that is initiated by limb trauma. They further suggest that nowadays there is proof that CRPS type I is a neurological disorder, and inferred that 'pathological evidence of nerve damage in patients classified as CRPS type I obviates distinction between CRPS-I and CRPS-II'.

Since the new terminology is a compromise, it may undergo modifications in the future after more quantitative clinical data and better analysis of the mechanisms have accumulated [21]. At present, there is extensive scientific identification of cellular and molecular mechanisms which lay the foundations for greater CRPS knowledge and its diagnosis and treatment [22]. Ten years after the IASP conference, new diagnostic criteria were defined by the Budapest Task Force in a new consensus conference [23]. The definition of CRPS may be refined or become a new definition. This is important because the denomination or definition of CRPS is changing in time as it once did for RSD. Whether CRPS will remain subdivided into two types as introduced by the IASP conference [6] or CRPS I and II subtypes will be reunited as expressed by Oaklander [22], or a new term will be created [11], future studies will decide. Although it has been widely used and has guided the research activities and 
clinical treatment for 60 years, the name 'reflex sympathetic dystrophy' must remain in the past. For the denomination of the syndrome it is necessary not to mislead any further research and treatment [24]. Until this happens, the authors consider it wise to listen to John Bonica's opinion in Merskey and Bogduk [6] that '...even if the adopted definitions... are not perfect they are better than the Tower of Babel conditions.... It is of utmost importance to achieve a widely accepted terminology for the syndrome. Speaking one language has proved vital for the improvement of the diagnosis and for treating patients with CRPS.

\section{Conclusion}

The new and more neutral term 'complex regional pain syndrome' will likely replace the traditional names 'reflex sympathetic dystrophy' and 'causalgia' in the scientific medical literature. The new terminology is now widely accepted by the medical professionals who are mostly engaged in the treatment of CRPS patients but not yet so in other medical spheres, for example radiology specialists. The names 'reflex sympathetic dystrophy' and to a lesser extent 'causalgia' are still used by some authors.

\section{References}

1 Mitchell SW, Morehouse GR, Keen WW: Gunshot Wounds and Other Injuries of Nerves. Philadelphia, Lippincott \& Co, 1864 (reprinted in Clin Orthop Relat Res 2007; 458:35-39).

$\checkmark 2$ Birklein F, Handwerker HO: Complex regional pain syndrome: how to resolve complexity? Pain 2001;94:1-6.

-3 Veldman PH, Reynen HM, Arntz IE, Goris RJ: Signs and symptoms of reflex sympathetic dystrophy: prospective study of 829 patients. Lancet 1993;342:1012-1016.

4 Angelova J: On the issue of defining the terminology of a frequently observed syndrome of the musculoskeletal system. Collection of resumes from the Anniversary Scientific Session '75 Years Medical Faculty - Sofia'. Sofia, Medical Academy, 1993, p.5.

5 Alvarez-Lario B, Aretxabala-Alcíbar Í, Alegre-López J, Alonso-Valdivielso JL: Acceptance of the different denominations for reflex sympathetic dystrophy. Ann Rheum Dis 2001;60:77-79.

6 Merskey H, Bogduk N: Classification of chronic pain: description of chronic pain syndrome and definitions of pain terms, ed 2. Seatle, IASP Press, 1994.

-7 Stanton-Hicks M, Jänig W, Hassenbusch S, Haddox JD, Boas R, Wilson P: Reflex sympathetic dystrophy: changing concepts and taxonomy. Pain 1995;63:127-133.

8 Bruehl S: An update on the pathophysiology of complex regional pain syndrome. Anesthesiology 2010;113:713-725.
-9 Jänig W, Baron R: Complex regional pain syndrome is a disease of the central nervous system. Clin Auton Res 2002;12:150-164.

10 Schott GD: Reflexsympatheticdystrophy. J Neurol Neurosurg Psychiatry 2001;71:291295.

11 Schott GD: Complex? Regional? Pain? Syndrome? Pract Neurol 2007;7:145-157.

12 Sudeck P: Ueber die acute entzündliche Knochenatrophie. Arch Klin Chir 1900;62:147156.

13 Goebel A: Complex regional pain syndrome in adults. Rheumatology 2011;50:1739-1750.

$\checkmark 14$ Zollinger PE, Tuinebreijer WE, Breederveld RS, Kreis RW. Can vitamin C prevent complex regional pain syndrome in patients with wrist fractures? A randomized, controlled, multicenter dose-response study. J Bone Joint Surg Am 2007:89;1424-1431.

15 Perez RS, Zollinger PE, Dijkstra PU, Thomassen-Hilgersom IL, Zuurmond WW, Rosenbrand KC, Geertzen JH, CRPS I Task Force: Evidence-based guidelines for complex regional pain syndrome type 1 . BMC Neurol 2010;10:20.

-16 Harden RN, Bruehl S, Galer BS, Saltz S, Bertram M, Backonja M, Gayles R, Rudin N, Bhugra MK, Stanton-Hicks M: Complex regional pain syndrome: are the IASP diagnostic criteria valid and sufficiently comprehensive? Pain 1999;83:211-219.
17 Van Rijn MA, Marianus J, Putter H, Bosselaar SRJ, Moseley GL, van Hilten JJ: Spreading of complex regional pain syndrome: not a random process. J Neural Transm 2011;118: 1301-1309.

18 Oaklander AL, Field HL: Is reflex sympathetic dystrophy/complex regional pain syndrome type I a small-fiber neuropathy? Ann Neurol 2009;65:629-638.

19 Albrecht PJ, Hines S, Eisenberg E, Pud D, Finlay DR, Connolly MK, Pare M, Davar G, Rice FL: Pathologic alterations of cutaneous innervation and vasculature in affected limbs from patients with complex regional pain syndrome. Pain 2006;120:244-266.

20 Oaklander AL, Rissmiller JG, Gelman LB, Zheng L, Chang Y, Gott R: Evidence of focal small-fiber axonal degeneration in complex regional pain syndrome-I (reflex sympathetic dystrophy). Pain 2006;120:235-243.

21 Baron R, Jänig W: Complex regional pain syndromes: taxonomy, diagnostic criteria, mechanisms of vascular abnormalities, edema, and pain. Behav Brain Sci 1997;20:437439.

22 Oaklander AL: RSD/CRPS: the end of the beginning. Pain 2008;139:239-240.

23 Harden RN, Bruehl S, Stanton-Hicks M, Wilson PR: Proposed new diagnostic criteria for complex regional pain syndrome. Pain Med 2007;8:326-331.

24 Coderre TJ: Complex regional pain syndrome: what's in a name? J Pain 2011;12:212. 